\title{
Transformation of Migration Rules from Local to Global Erkan ${ }^{ \pm}$
}

\begin{abstract}
In the 21st century, the scope and the size of migration are more different than previous centuries. The reason behind this is that there are no more global wars or conflicts between states and the economic developments reached the highest levels for some of the countries. Moreover, states try to increase their industrial level. Hence, the conflicts and the economic development level shape migration routes and the destination country. In this context, I will utilize geopolitics and economic development levels to classify countries. As a result of the end of global conflicts and global war, economic conditions became main determinant for migrations in the globalized world in the 21st century. In the 20th century, the scope of migration was small compared to 21st century because of various reasons. Standardized education and high level industrialization are of two main reasons. In the 21st century, the industrialization hit the top level of the world history and education took standardized structure among particular countries. In this research, all countries will be examined in detail with respect to UN Data. Furthermore, the following questions are targeted to be answered: Does migration flow from less developed countries to developed countries? Do developed countries accommodate more immigrants in their borders?
\end{abstract}

Keywords: immigrants; emigrants; developed countries; less developed countries.

\section{Introduction}

Migration is evolving and transforming regularly during the history. Conditions, reasons and effects of migration are also changing in time. However, some rules of migration still stay same since the first definition of the rules of migration.

Ernst Georg Ravenstein was one of the pioneers for migration studies. He is also groundbreaker for migration studies in the world. He defined seven rules of migration in 1885 . Nowadays, many parts of that specification are still applicable. I won't focus on Ravenstein's laws of migration but I benefit from one of his laws in order to establish theoretical perspective of the article. It also fits well with my hypothesis and I try to check my hypothesis in this article with support of the UN data.

There are two hypotheses that I check on with the data. However, Ravenstein's fifth law of migration is pretty ideal initial point for me. World is global now and borders of states are not strict anymore for the people crossing the borders. At the start of the industrial revolution people migrate from rural areas to industrial centers in their countries. Migration to other countries to work is not too easy for people in the $19^{\text {th }}$ century. Yet, world

\footnotetext{
${ }^{ \pm}$Hakan Sezgin Erkan, PhD Candidate, Yeditepe University, Istanbul, Turkey.

E-mail: hakan.erkan@yeditepe.edu.tr.
} 
has changed and globalization spread all over the world. Today, people have chance to migrate from their countries to other countries in order to work. So, in my opinion, migration turned into a state of the global. Hence, my first hypothesis is that migration should flow from less developed to developed countries to a large extent considering any kinds of events. Reasons of migration may be finding a job; running from an armed conflict, war etc. but people would prefer industrial and commercial centers to continue their lives. As a related to my first hypothesis, my second hypothesis is that developed countries preserve more immigrants. What is more, people who live in least developed countries immigrate to more developed countries.

\section{Migration Flows}

In his fifth law, Ravenstein argued that "Migrants proceeding long distances generally go by preference to one of the great centres of commerce or industry" (Ravenstein, 1885, p. 199). This law is completely mentions about migration from rural areas to industrial areas. However, the critical point is that that rule mentions about migration inside the country. This is why migration to any other countries during $19^{\text {th }}$ century was not one of the easiest things for the people because of evident reasons. Firstly, language is one of the main problems for people. Factories need people who can speak the native language fluently so as to achieve the mutual understanding. Secondly, crossing border is not as easy as today at the time under the conflicts of the states in European continent. Thirdly, there were not enough job opportunities previously for everybody. Factories did not prefer foreign workers. Fourthly, specialization of people was not as various as it was in the $19^{\text {th }}$ century. Lastly, education was not universal for every state. Every state had its own system and educated its people with respect to their own system.

Nowadays, that rule is also valid all around world. This is why, language is no more a problem for the people. People can easily learn different languages than the previous century. In other words, migrants may speak the language of the state which they immigrate. Secondly, crossing border is not as difficult as in the previous century if people have good education and qualification. Competition between countries and companies is increasing day by day. Hence, states regulate its laws in order to take high qualified and educated people. Thirdly, globalization and high level of specialization provide more job opportunities than previous century for people. Due to many high level qualified people, companies and states try to choose best of them. Fourthly, education is universal nearly every part 
of the developing world. When people study in engineering or social sciences, they have chance to reach every document in different countries and the universities always update its curriculum with respect to changes in the field. Lastly, gap of life standards between states is also increasing day by day. Hence, there are too many reasons to migrate from less developed to more developed countries in the $20^{\text {th }}$ and $21^{\text {st }}$ centuries.

All in all, these arguments seem to support my hypotheses. However, I also test my hypotheses with the UN data. There are two types of data which are beneficial for me. These are numbers of migrants and GDP of countries with according to years. When I compare these two data, result may be beneficial to test my hypotheses. My time interval is five years. In my opinion, five years is a good interval to understand change of economic condition of countries and for the measurement of migrant numbers in countries. Hence, I started my dataset from 1990 and I finished it in 2015. I classified countries in every five year and with respect to number of immigrants and GDP. According to these data, I try to test whether countries which have high GDP level accommodate more immigrants in their borders. Thus, I also have chance to test my hypotheses at once.

I classified countries forty four by forty four with respect to number of immigrants and their GDP level. At the end of comparison, I try to determine intersection points of two lists. Here is how I have conducted the classification in the list. I classified the 44 most immigrated countries as the group $A$ and then put the 44 countries under B, C, and D class.

\begin{tabular}{|l|c|}
\hline \multicolumn{2}{|l|}{ Country Ranking Based on the Number of Migrants Hosted } \\
\hline A Countries & $1<\mathrm{A}<44$ \\
\hline B Countries & $45<\mathrm{B}<91$ \\
\hline C Countries & $90<\mathrm{C}<136$ \\
\hline D Countries & $136<\mathrm{D}$ \\
\hline
\end{tabular}

In a similar vein, I did a second ranking according to the countries' GDPs and I listed those 44 each. I classified these countries as X, Y, Z, T. Below can be seen a country ranking based on GDP.

\begin{tabular}{|c|c|}
\hline \multicolumn{2}{|c|}{$\begin{array}{c}\text { Country Ranking Based on the GDP of } \\
\text { Countries }\end{array}$} \\
\hline X Countries & $1<A<44$ \\
\hline Y Countries & $45<B<91$ \\
\hline Z Countries & $90<C<136$ \\
\hline T Countries & $136<D$ \\
\hline
\end{tabular}


After this ranking, it will be practical to compare the two groups in order to test my hypothesis. For this reason, I need to analyze the relation between $A$ Countries and $X$ Countries to test my hypothesis. As the intersection point of the two hypotheses, if the top immigrant countries are the ones who have the highest GDP, A Countries and X Countries should resemble each other at a high rate.

To measure this resemblance, I aim to compare these lists since 1990, with 5-year intervals, until 2015 and draw the mathematical ratios.

\begin{tabular}{|r|r|l|}
\hline \multicolumn{3}{|c|}{1990} \\
\hline 30 & $\mathrm{X}$ & $1<\mathrm{A}<45$ \\
\hline 12 & $\mathrm{Y}$ & $44<\mathrm{B}<91$ \\
\hline 1 & $\mathrm{Z}$ & $90<\mathrm{C}<136$ \\
\hline 1 & $\mathrm{~T}$ & $136<\mathrm{D}$ \\
\hline
\end{tabular}

30 out of 44 most migrated countries in 1990 also have the highest GDPs. In other words, 30 countries in the $A$ and $X$ lists are the same ones. Additionally, List $A$ and List $X$ share similarity at the rate of 68 percent (Nations, 2015).

\begin{tabular}{|r|r|l|}
\hline \multicolumn{3}{|c|}{1995} \\
\hline 32 & $X$ & $1<\mathrm{A}<45$ \\
\hline 9 & $\mathrm{Y}$ & $44<\mathrm{B}<91$ \\
\hline 3 & $\mathrm{Z}$ & $90<\mathrm{C}<136$ \\
\hline 0 & $\mathrm{~T}$ & $136<\mathrm{D}$ \\
\hline
\end{tabular}

(Nations, 2015).

\begin{tabular}{|r|r|l|}
\hline \multicolumn{3}{|c|}{2000} \\
\hline 30 & $X$ & $1<\mathrm{A}<45$ \\
\hline 12 & $\mathrm{Y}$ & $44<\mathrm{B}<91$ \\
\hline 2 & $\mathrm{Z}$ & $90<\mathrm{C}<136$ \\
\hline 0 & $\mathrm{~T}$ & $136<\mathrm{D}$ \\
\hline
\end{tabular}

2015).

\begin{tabular}{|r|r|l|}
\hline \multicolumn{3}{|c|}{2005} \\
\hline 32 & $\mathrm{X}$ & $1<\mathrm{A}<45$ \\
\hline 10 & $\mathrm{Y}$ & $44<\mathrm{B}<91$ \\
\hline 2 & $\mathrm{Z}$ & $90<\mathrm{C}<136$ \\
\hline 0 & $\mathrm{~T}$ & $136<\mathrm{D}$ \\
\hline
\end{tabular}

It is almost same rates in 1995, even a slight increase in the similarity between $X$ and A Countries. Departing from this inclination, 32 out of 44 countries with the most migrants have the greatest GDPs at the same time. In other words, List $X$ and List $A$ share a similarity at the rate of 72 percent

In 2000, there is not a big change in the similarity ratio between $X$ Countries and $A$ Countries. It is evident that 30 out of 44 countries with the most migrants have the greatest GDPs at the same time. Looking at the percentage, List $X$ and List $A$ share a similarity at the ratio of 68 percent (Nations,

In 2005, similarity ratio between List $X$ Countries and List A Countries displays an increase compared to previous 5 years. Based on this, 32 out of 44 countries with the most migrants have the greatest GDPs at the same time. In other words, the similarity ratio which shows a decrease at the rate of 4 percent from 1995 to 2000 came to the same level in 2015 as in 1995. 
Hence, the List $\mathrm{A}$ and the List $\mathrm{X}$ share a similarity at the rate of 72 percent in 2005 (Nations, 2015).

\begin{tabular}{|r|r|l|}
\hline \multicolumn{3}{|c|}{2010} \\
\hline 31 & A & $1<$ A $<45$ \\
\hline 10 & B & $44<$ B $<91$ \\
\hline 2 & C & $90<C<136$ \\
\hline 0 & D & $136<D$ \\
\hline
\end{tabular}

2010 does not see a substantial change compared to the other years. 31 out of 44 countries with the most migrants have the greatest GDPs at the same time. Despite a small decrease in the similarity ratio between the List $A$ and the List $X$, the resemblance still holds 70 percent. (Nations,

2015).

\begin{tabular}{|r|r|l|}
\hline \multicolumn{3}{|c|}{2015} \\
\hline 31 & A & $1<\mathrm{A}<45$ \\
\hline 11 & B & $44<\mathrm{B}<91$ \\
\hline 1 & C & $90<\mathrm{C}<136$ \\
\hline 0 & D & $136<\mathrm{D}$ \\
\hline
\end{tabular}

Lastly, the similarity ratio in 2015 is the same with the 2010 figures. 31 out of 44 countries with the most migrants have the greatest GDPs at the same time. Compared to 2010, the similarity ratio between the List $X$ and the List $A$ has not changed. The resemblance between these two lists

maintains 70 percent in 2015. (Nations, 2015).

After a comparison of migration and welfare relationship from 1990 to 2015 with 5-year intervals, we see a high ratio of similarity. Observing the countries with the most migrants and the countries with the highest GDP until 2015 with 5 -year periods, we see 70 percent similarity ratio.

\section{Conclusion}

When putting forward the similarity rates from 1990 to 2015 with 5-year periods, I may have taken the chance to test my hypotheses. Accordingly, the migration flows from the developed countries to under-developed ones. While migrant population is high in the developed countries, it is rather low in the under-developed ones. My second hypothesis that the developed countries host more migrants economically has been proven at large extent. It is apparent that 70 percent of economically developed 44 countries are also the ones which host the most migrants within their borders. From 1990 to 2015, the ratio hasn't been under 68 percent.

With this approach, I have tested the hypotheses and have observed that the fifth Law Ravenstein designed for England - that the migration moves from the rural to the urban- transformed into a move from the underdeveloped countries to the developed ones. In other words, while the populations in the $19^{\text {th }}$ and $20^{\text {th }}$ migrated from economically underdeveloped regions to the developed regions within the country, at the end of $20^{\text {th }}$ century and in the $21^{\text {st }}$ century, the migration happens from 
economically underdeveloped countries to the developed ones. So to say, economically developed countries host the most migrants within their borders.

There are certainly exceptions to this situation that occur due to the temporary border conflicts, civil wars, diseases, epidemics and natural disasters. The only example as a country that has the most migrants inside but economically underdeveloped can be seen in 1990. There had been a heavy migration flow from Malawi to Mozambique and Mozambique became one of the 44 countries with the most migrants despite its economic underdevelopment.

In conclusion, applying Ravenstein's migration theory on a global scale, the migration flows from underdeveloped countries to the developed ones whether it is on country level or global sample. In other words, it is evident that the countries with high economic development level are also the ones with the most migrant populations within their borders.

\section{References}

Bank, W. (2017, December 30). GDP Data. Retrieved from The World Bank Web site: https://data.worldbank.org/indicator/NY.GDP.MKTP.CD

Nations, U. (2015, December 31). Total International Migrant Stock. Retrieved from International migrant

stock:

http://www.un.org/en/development/desa/population/migration/data/estimates2/ data/UN_MigrantStockTotal_2015.xIsx

Ravenstein, E. G. (1885). The Laws of Migration. Journal of the Statistical Society of London, 167-235. 